\title{
Design of a High-Loaded Clarifier and Its Application on the Treatment of Overflow Rainwater
}

\author{
Jianshe Tang* a, Xianhuai Huang ${ }^{\text {b }}$, Feng Zhao ${ }^{c}$, Jiansheng Qiao ${ }^{d}$, \\ and Lingxia $\mathrm{Li}^{\mathrm{e}}$ \\ School of Environment and Energy Engineering, Anhui University of Architecture, Hefei, \\ P. R. China. \\ atjs28@126.com, 'xhhuang2@gmail.com, 'sbkzf@aiai.edu.cn, jianshengqiao@aiai.edu.cn, \\ elilingxia1987@126.com
}

Keywords: Overflow Rainwater, Lamella Clarifier, High-Loaded, Treatment.

\begin{abstract}
Overflow rainwater is a serious environmental problem nowadays, which attracted the most researchers' attentions. Accordingly, effective and economic treatment of overflow rainwater is highly required. This study aimed to design a high-loaded clarifier equipment and developed an innovative overflow rainwater treatment. The high-loaded clarifier equipment was consisted of grid, pump, coagulant, reactor, and the most important part of lamella clarifier with serried metal plates. The removal of pollutants in overflow rainwater with the high-loaded clarifier equipment was evaluated. The pollutions removal rate of overflow rainwater was investigated with $65 \% \mathrm{COD}$ and $90 \%$ SS, approximately.
\end{abstract}

\section{Introduction}

Surface water quality is negatively influenced by stormwater runoff. The overflow rainwater effect is the main impetus for pollutants transportations and increases pollutant loads to surface water especially [1]. Some relevant foreign scholars focus on the definition, causes, effects, as well as the regularity of the pollutant flush by runoff from small watershed and regional scale. Also many Chinese scholars pay attention to describing the overflow rainwater phenomenon accurately, the regularity of the pollutant flush, engineering practice guidance of treatment, and so on [2].

As Chinese urbanization developing, urban stormwater runoff pollution and emission characteristics have always been investigated intensively [3,4]. Hefei is a well-known city in the world for its rapid rhythm of development. But in recent years with the rapid economic and social development, the degradation of the Nanfei River quality is becoming increasingly serious. Urban storm runoff has been a serious pollution source of the river. It is important to find out the rule of pollutants removal from overflow rainwater.

High-loaded clarifier equipment was designed and set up near the Nanfei River. The efficiency of the high-loaded clarifier equipment in the treatment of overflow rainwater was investigated.

\section{Experimental Facilities and Method}

The High-Loaded clarifier Equipment. A lamella clarifier features a rack of inclined metal plates. Metal plates could cause flocculated material to precipitate from water. Gravity settlers are sized on the basis of upflow rate of the liquid and settling area. On a clarifier the settling area is the tank surface and on lamella settlers it is the total area of the inclined plates projected on a horizontal surface. This reduces the footprint of lamella settlers by about $90 \%$ as compared to clarifiers and consequently less land is required [5].

In our designed equipment, serried metal plates were adopted inside the high-loaded clarifier, which could promote the SS and COD removal rate of overflow rainwater. The high-loaded clarifier equipment was characterized as high removal rate of pollutions, hydraulics impact resistance, and stable effluent in terms of the results of experiments.

The high-loaded clarifier equipment was consisted of: 
I : 2 sewage pumps: flow rate of $50 \mathrm{~m}^{3} / \mathrm{h}$, delivery head of $15 \mathrm{~m}$;

II : 1 mechanical reactor: $6.0 \times 2.0 \times 2.6 \mathrm{~m}^{3}$, the effective volume of $25 \mathrm{~m}^{3}$, hydraulic retention time of $30 \mathrm{~min}$;

III: 1 clarifier (Precipitator): $2.0 \times 2.5 \times 5.5 \mathrm{~m}^{3}$. fixed 20 plate racks inside, the effective volume of $20 \mathrm{~m}^{3}$, surface loading rates of $12.5 \mathrm{~m}^{3} /\left(\mathrm{m}^{2} \cdot \mathrm{h}\right)$, hydraulic retention time of $24 \mathrm{~min}$;

$\mathrm{IV}: 2$ mixers.

The site of clarifier equipment fixed and the schematic diagram of clarifier were shown in Fig. 1 and Fig. 2, respectively. Suspended Solid (SS) and Chemical Oxygen Demand (COD) were determined by national standard analysis method of China.

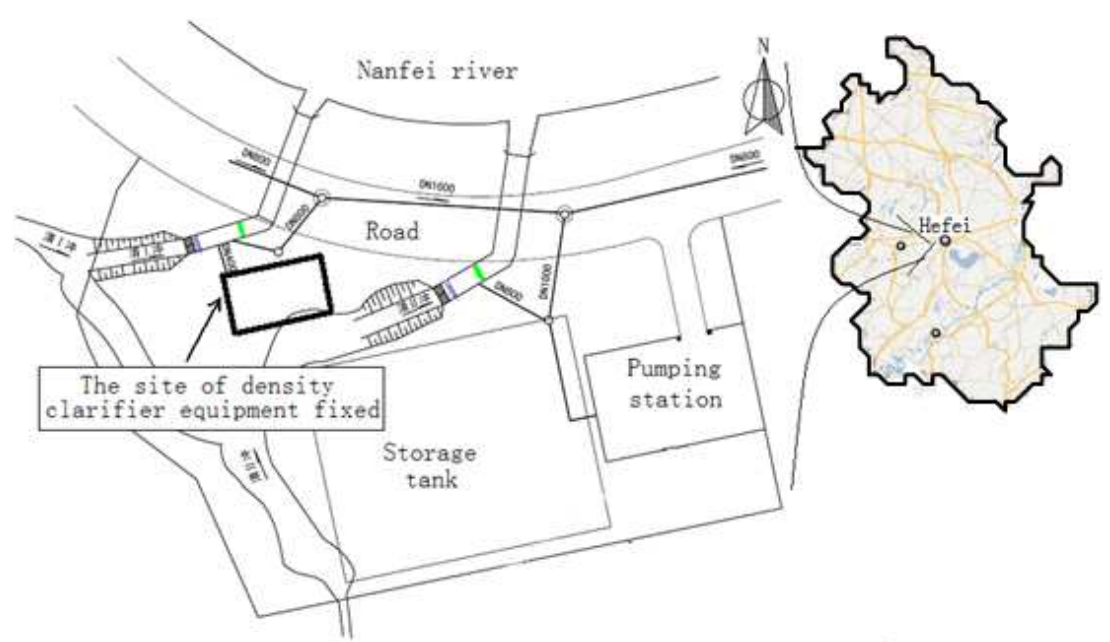

Figure 1. The site of the high-loaded clarifier equipment set up

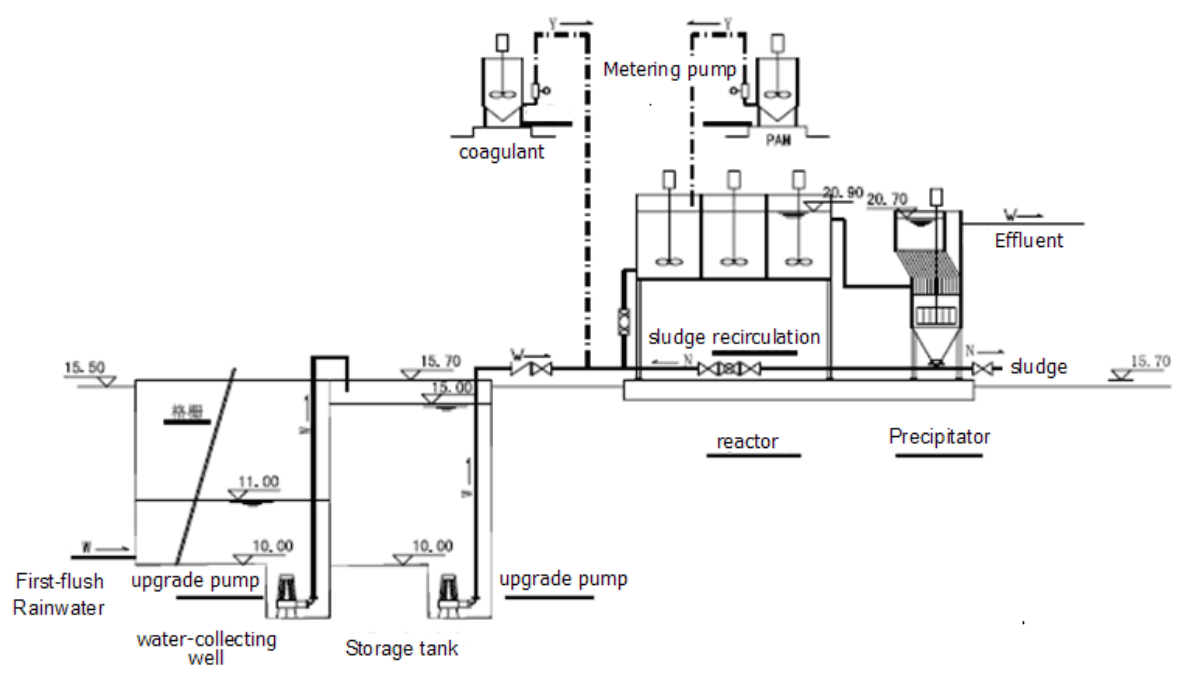

Figure 2. The schematic diagram of clarifier equipment

\section{Result}

The Effect of Flow. The raw water with pollution of $357 \sim 765 \mathrm{mg} / \mathrm{L} \mathrm{SS}$ and $216 \sim 565 \mathrm{mg} / \mathrm{L}$ COD were treated by high-loaded clarifier at the condition of different flow rate. Table 1 given out the results of pollutions removal rate. As shown in table 1, it can be concluded that the COD removal rate increased with increasing flow rate, while as the SS removal rate was not good relation with the flow rate. 
Table 1. The pollutions removal rate at the different flow rate

\begin{tabular}{|c|c|c|c|c|c|}
\hline $\begin{array}{c}\text { Sample } \\
\text { No }\end{array}$ & $\begin{array}{c}\text { Flow } \\
\text { rate } \\
\left(\mathrm{m}^{3} / \mathrm{h}\right)\end{array}$ & $\begin{array}{c}\text { Raw water } \\
\text { SS }(\mathrm{mg} / \mathrm{L})\end{array}$ & $\begin{array}{c}\text { Removal rate } \\
(\%)\end{array}$ & $\begin{array}{c}\text { Raw water COD } \\
(\mathrm{mg} / \mathrm{L})\end{array}$ & $\begin{array}{c}\text { Removal rate } \\
(\%)\end{array}$ \\
\hline 1 & 45 & 357 & 85.7 & 216 & 53.2 \\
\hline 2 & 50 & 482 & 84.3 & 337 & 57.3 \\
\hline 3 & 55 & 673 & 89.2 & 473 & 64.2 \\
\hline 4 & 60 & 765 & 91.6 & 350 & 63.8 \\
\hline 5 & 65 & 462 & 80.7 & 565 & 66.9 \\
\hline 6 & 70 & 575 & 83.4 & 375 & 55.2 \\
\hline
\end{tabular}

The Treatment Efficiency to Real Samples. The high-loaded clarifier equipment was run to remove the pollution of overflow rainwater between May 10, 2011 and July 20, 2011 in Hefei city. The quality of first-flush was determined with COD concentration ranging of $280 \sim 1900 \mathrm{mg} / \mathrm{L}$, and SS concentration ranging of $600 \sim 2000 \mathrm{mg} / \mathrm{L}$. Also the outlet of storage tank was checked with water quality of $158 \sim 565 \mathrm{mg} / \mathrm{L} \mathrm{COD}$ and of $161 \sim 935 \mathrm{mg} / \mathrm{L} \mathrm{SS}$. Then the water was treated by coagulation and coagulation process further at flow rate of $60 \mathrm{~m} 3 / \mathrm{h}$. The results were shown in table 2 . The concentration of $25 \mathrm{mg} / \mathrm{L}$ coagulant PAC was adopted. The approximately $65 \%$ removal rate of COD and $90 \%$ removal rate of SS were obtained in the experiments.

Table 2. The pollutions removal rate of real sample

\begin{tabular}{|c|cc|c|c|c|c|}
\hline $\begin{array}{c}\text { Sample } \\
\text { No }\end{array}$ & Data & $\begin{array}{c}\text { Raw water SS } \\
(\mathrm{mg} / \mathrm{L})\end{array}$ & $\begin{array}{c}\text { Removal rate } \\
(\%)\end{array}$ & Data & $\begin{array}{c}\text { Raw water COD } \\
(\mathrm{mg} / \mathrm{L})\end{array}$ & $\begin{array}{c}\text { Removal rate } \\
(\%)\end{array}$ \\
\hline 1 & $2011-6-14$ & 161 & 68.3 & $2011-6-14$ & 383 & 63.4 \\
\hline 2 & $2011-7-17$ & 462 & 80.7 & $2011-6-17$ & 357 & 53.5 \\
\hline 3 & $2011-6-24$ & 318 & 78.6 & $2011-7-17$ & 565 & 67.0 \\
\hline 4 & $2011-6-10$ & 213 & 82.2 & $2011-5-11$ & 158 & 44.3 \\
\hline 5 & $2011-7-4$ & 935 & 88.9 & $2011-6-24$ & 282 & 44.1 \\
\hline 6 & $2011-7-4$ & 765 & 91.6 & $2011-7-4$ & 350 & 63.8 \\
\hline 7 & $2011-6-24$ & 432 & 89.6 & $2011-6-10$ & 387 & 36.1 \\
\hline 8 & $2011-6-10$ & 315 & 74.9 & & & \\
\hline
\end{tabular}

\section{Summary}

A high-loaded clarifier equipment was designed, which was consisted of grid, pump, coagulant, reactor, and the most important part of lamella clarifier with serried metal plates. When the high-loaded clarifier equipment was adopted to treatment the overflow rainwater, the COD removal rate increased with increasing flow rate, while the SS removal rate was not good relation with the flow rate. The pollutions removal rate of overflow rainwater was investigated with $65 \%$ COD and $90 \% \mathrm{SS}$, approximately.

\section{Acknowledgements}

This work was financially supported by the National Natural Science Foundation of China (No. 51078001), Major Science and Technology Program for Water Pollution Control and Treatment (No. 2009ZX07103-004) and Natural Science Foundation of Anhui Provence (11040606M99). First Author is corresponding author. 


\section{Reference}

[1] M. Mrowiec: Water Sci. and Tech. Vol. 62(2010), p.2167-2174

[2] J. L. Wang, W. Che, W. Zhang, B. Y. Wang, G. Q. Pan and H. X. Yi: Bioinformatics and Biomedical Engineering, (iCBBE) 2011 5th International Conference, Vol. 10(2011), p.1

[3] T. J. Tian, T. Li, S. M. He, A. C. Zhong and D. Zhao: Environmental Science and Information Application Technology, 2009. ESIAT 2009. International Conference, Vol. 2(2009), p.359

[4] W. Wang, W. Ouyang and F. H. Hao: Mechanic Automation and Control Engineering (MACE), 2010 International Conference, Vol. 10(2009), p.4721

[5] H.Soderlund: Vatten, Vol:37(1981),p.166 